\title{
CARACTERIZAÇÃO AMBIENTAL E FLORÍSTICA DO ESTRATO ARBÓREO DO REMANESCENTE DE FLORESTA OMBRÓFILA MISTA SITUADO NO CAMPUS BARIGÜI DA UNIVERSIDADE TUIUTI DO PARANÁ, CURITIBA, PR, BRASIL
}

\author{
Fernando Esteban Montero de Oliveira, Aurea Portes Ferriani, Rafael Rosenstock Völtz \\ fernandomontero88@hotmail.com, apferriani@ig.com.br,rfeltz@ig.com.br
}

RESUMO: O presente trabalho teve como objetivo caracterizar a composição florística de indivíduos arbóreos com $C A P \geq 15 \mathrm{~cm}$ presentes em um remanescente de Floresta Ombrófila Mista, localizado no campus Barigüi da Universidade Tuiuti do Paraná-UTP, município de Curitiba PR. Todos os indivíduos foram amostrados através da coleta de material vegetativo e quando possível material fértil, com identificação realizada por especialistas. Foram identificadas 33 espécies entre nativas e exóticas, divididas em 30 gêneros e 23 famílias botânicas. Foram identificadas famílias representativas da formação original, entre as quais Araucariaceae, Aquifoliaceae, Lauraceae, Myrtaceae, Podocarpaceae e Tiliaceae e sub-bosque preservado contendo indivíduos com alturas e diâmetros variados, o que indica a potencial regeneração da área. Exemplares de espécies exóticas como Pinus elliottii , Hovenia dulcis, Eriobotrya japonica, Morus nigra, Hibiscus rosa-sinensis e Citrus arantium também foram verificados, indicando necessidade de um futuro manejo. As informações obtidas nesta pesquisa constituem a primeira etapa de levantamentos para a utilização da área em futuras pesquisas e ações de conservação e educação ambiental.

Palavras-chave: Fragmento florestal, floresta urbana, diagnóstico ambiental

\begin{abstract}
This work aimed to know the floristic composition of tree elements with CAP $\geq 15 \mathrm{~cm}$ in Mixed Ombrophylous Forest fragment, at University Tuiuti of Paraná - UTP campus Barigüi, Curitiba - PR. All the plants were sampled by vegetative plant collection and fertile material with identification made for specialists. Were recognized 33 between native and exotic species, divided in 30 genus and 23 botanic families. Representative families by original formation among Araucariaceae, Aquifoliaceae, Lauraceae, Myrtaceae, Podocarpaceae and Tiliaceae, corresponding to this biome and preserved understory with variable heights that indicates potential restoration in the area. Exotic species as Pinus elliotii, Hovenia dulcis, Morus nigra, Hibiscus rosa-sinensis, Citrus aurantium and Eriobotrya japonica were verified, showing necessity of future management. The information obtained in this study constitutes the first survey to utilization of the area in future researches and conservation actions including Enviromental Education.
\end{abstract}

Keywords: Forest Fragment, Urban forestry, Environmental diagnosis 
(Revista Eletrônica do PPGEAmb-CCR/UFSM) ISSN:

\section{INTRODUÇÃO}

Fernandez (2004) comenta que a explosiva expansão populacional e econômica da humanidade nos últimos séculos transformou o que antes eram grandes áreas contínuas de florestas em paisagens mosaico, formadas por manchas remanescentes das florestas originais, cercadas por áreas alteradas de várias formas como plantações, pastagens e assentamentos urbanos.

Segundo Negrelle e Leuchtenberger (2001) no início do século XX a Floresta Ombrófila Mista ocupava aproximadamente 20 milhões de hectares. Enquanto atualmente estima-se apenas $1 \%$ desta área (SANQUETTA et al., 2006), representada por remanescentes em estágio avançado de sucessão, fragmentados ao longo dos três planaltos (FUPEF, 2001). O estado do Paraná conta com menos de $10 \%$ da cobertura florestal original (PEREIRA, 2004).

No contexto do município de Curitiba, Borgo (2002) pontua que a Floresta Ombrófila Mista limita-se a fragmentos isolados com diferentes graus de conservação, localizados em sua maioria em parques e bosques municipais, mantidos através de legislação específica.

A Lei n. ${ }^{\circ} 9.806$ de 03 de janeiro de 2000 considera Bosques Nativos os maciços de mata nativa representativos da flora do município de Curitiba, que visem à preservação de águas existentes, do habitat da fauna, da estabilidade dos solos, da proteção paisagística e manutenção da distribuição equilibrada dos maciços florestais. Dessa maneira, a permanência dessas formações pode constituir verdadeiros "laboratórios a céu aberto", além de contribuírem para a amenização de efeitos ambientais como excesso de ruídos e "ilhas de calor", por exemplo.

Grey e Deneke (1978) classificam as florestas urbanas em públicas e privadas. As públicas incluem os parques, a arborização de vias, espaços e construções públicas, compreendendo áreas de hospitais, cemitérios, escolas, museus e penitenciárias, entre outras. As florestas urbanas privadas são terrenos de áreas residenciais, comerciais e industriais. Para esses autores, o manejo adequado das florestas urbanas é uma responsabilidade tanto pública como privada.

A conversão de florestas em habitats antropogênicos constitui uma agressão à biodiversidade florestal no planeta. A substituição de florestas naturais por florestas plantadas com fins comerciais é tão agressiva quanto à agricultura ou urbanização (BARBOSA et al, 2009). A fragmentação - natural ou antrópica - é uma das perturbações mais significativas (BORGO, 2002), causando distúrbio e modificações na variedade de espécies selvagens, exterminando as espécies nativas e promovendo o estabelecimento de espécies exóticas (GARCILLÁN, 2009). Nos estados das regiões sul e sudeste encontram-se raros fragmentos de vegetação, sendo os únicos laboratórios disponíveis para pesquisas (RODE, 2008).

Diante da necessidade de conservação de áreas florestadas na cidade de Curitiba, conhecimento da composição de flora e fauna destas áreas, possibilidade de destinação da área para pesquisas básica e aplicada pela comunidade acadêmica e desenvolvimento de ações educativas destinadas ao público externo, o presente trabalho teve como objetivo diagnosticar e caracterizar a composição florística do estrato arbóreo do remanescente de Floresta Ombrófila Mista existente no campus Barigüi da Universidade Tuiuti do Paraná. 


\section{Monografias Ambientais}

(Revista Eletrônica do PPGEAmb-CCR/UFSM) ISSN:

\section{MATERIAL E MÉTODOS}

\section{FIGURA 1 - IMAGEM DO LOCAL DE ESTUDO SITUADO NO CAMPUS BARIGÜI DA UNVERSIDADE TUIUTI DO PARANÁ}

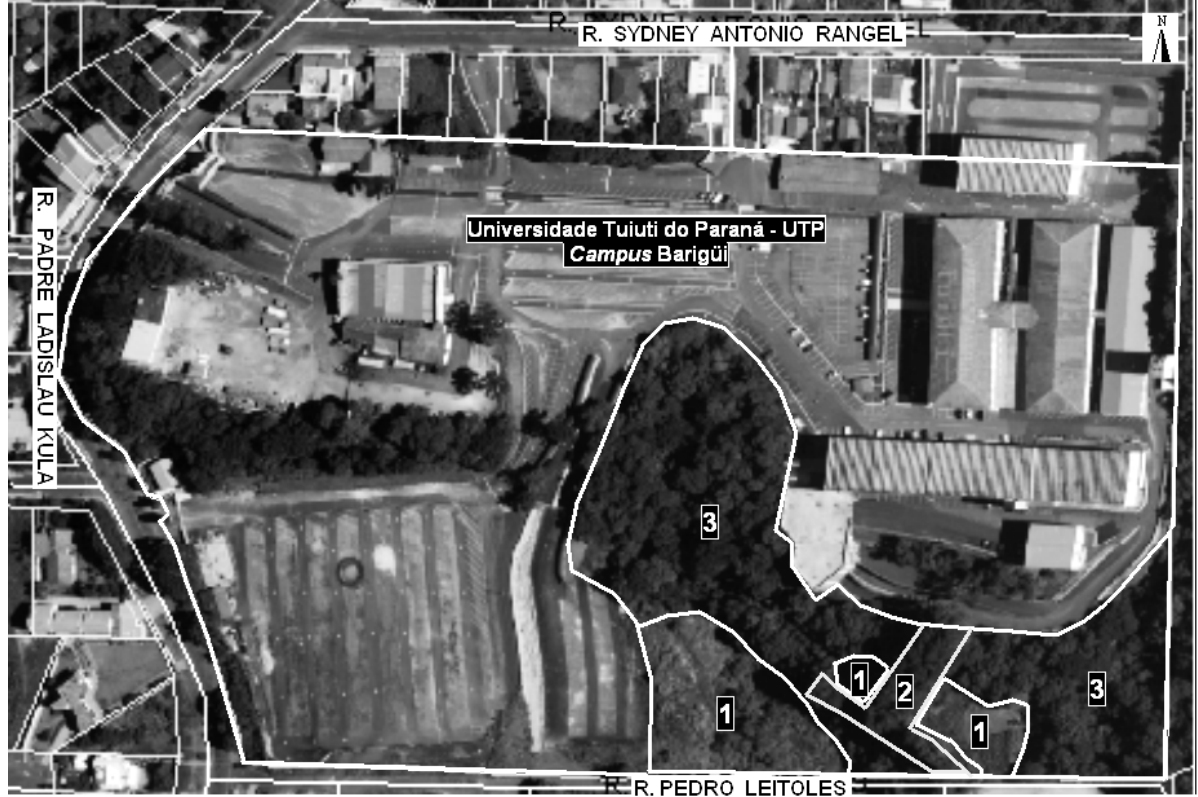

(1). Áreas de vegetação rasteira representada por gramíneas e "vassouras"

(2). Alinhamento de (pinus) Pinus elliottii

(3). Áreas de vegetação arbórea

Fonte: adaptado de CURITIBA, 2007.

O local de estudo está situado no Campus Barigüi da Universidade Tuiuti do Paraná - UTP (Figura 1), entre as coordenadas J 669028.55 m E; 7186952.14 m S, confrontando com a Rua Pedro Leitoles, no bairro Santo Inácio, possuindo área de 2,15 ha. Este se encontra dentro da bacia do rio Barigüi que apresenta $144.43 \mathrm{~km}^{2}$, representando $33 \%$ da área do município de Curitiba (CURITIBA, 2004).

De acordo com a classificação de Köeppen, o clima da região é do tipo Cfb, característico de áreas planas dos planaltos, subtropical úmido mesotérmico de verões frescos, inverno com geadas freqüentes, sem estação seca (MAACK, 1968; IAPAR, 1978) com temperatura média do mês mais frio abaixo de $18{ }^{\circ} \mathrm{C}$ e temperatura média do mês mais quente abaixo de $22{ }^{\circ} \mathrm{C}$ (CURCIO et al., 2002). A umidade relativa do ar média em torno de $85 \%$, e a precipitação em torno de $1.400 \mathrm{~mm}$ anuais (FUNPAR, 2002). A altitude média do local de estudo está em torno de $900 \mathrm{~m}$.

Para o levantamento florístico de espécies arbóreas, foi coletado material vegetativo dos indivíduos com circunferência à altura do peito $(C A P) \geq 15 \mathrm{~cm}$, medido com fita métrica. Árvores com mais de um fuste, na altura citada, foram incluídas quando pelo menos uma delas apresentava o perímetro mínimo exigido.

Os estágios sucessionais de vegetação secundária caracterizados no presente estudo baseiam-se na Resolução CONAMA n. 002, de 18 de março de 1994 (Tabela 1). 
TABELA 1 - PARÂMETROS PARA CLASSIFICAÇÃO DOS ESTÁGIOS SUCESSIONAIS DE VEGETAÇÃO SECUNDÁRIA

\begin{tabular}{cccc}
\hline & INICIAL & INTERMEDIÁRIA & AVANÇADO \\
$\mathrm{N}^{\circ}$ de estratos & 1 & $1-2$ & $\geq 2$ \\
$\mathrm{~N}^{\circ}$ de espécies lenhosas & $1 \mathrm{a} 10$ & $5-30$ & $\geq 30$ \\
Altura das espécies lenhosas do & Até 10 & $8-17$ & $>30$ \\
dossel $(\mathrm{m})$ & & & \\
Amplitude diamétrica & PEQUENA & MÉDIA & GRANDE \\
Amplitude de altura & PEQUENA & MÉDIA & GRANDE \\
Gramíneas & ABUNDANTES & POUCAS & RARAS \\
\hline
\end{tabular}

Fonte: adaptado de CONAMA, 1994.

A coleta do material vegetativo foi efetuada por meio de caminhadas visando atingir a totalidade da área, com utilização de podão. Coletou-se material vegetativo de todas as espécies encontradas e quando possível material reprodutivo. As técnicas de coleta, prensagem, secagem e herborização seguiram as orientações de IBGE (1991) e Fidalgo e Bononi (1989). O material coletado foi desidratado em estufa (EFC - Herbário Escola de Florestas de Curitiba e HbUTP Herbário da Universidade Tuiuti do Paraná) e levado para identificação de especialistas da Universidade Federal do Paraná, Dr. Carlos Velloso Roderjan e Dra. Yoshiko Kuniyoshi, ambos do curso de Engenharia Florestal. A grafia correta dos nomes científicos foi consultada em: Missouri Botanical Garden, 2009.

Todas as espécies listadas, após receberem os processos de herborização constituíram as primeiras exsicatas incluídas no Herbário da Universidade Tuiuti do Paraná - HbUTP. Este herbário encontra-se em processo de construção e reestruturação devido ao incêndio ocorrido no Campus Champagnat da Universidade, onde todo o material foi danificado. Wagner Luiz Gogola (2009) em dados não publicados, confeccionou um manual básico de coleta, desidratação e montagem de exsicatas, destinado à reestruturação do HbUTP.

O trabalho de campo totalizou 36 horas, distribuídas em nove coletas realizadas no período de julho a novembro de 2009.

\section{RESULTADOS E DISCUSSÃO}

A tabela 2 apresenta a relação de espécies identificadas na área do campus Barigüi da Universidade Tuiuti do Paraná ao longo das nove coletas. Foram encontradas 33 espécies, distribuídas em 30 gêneros e 23 famílias botânicas. Do total, 32 indivíduos foram identificados até o nível de espécie e um indivíduo até nível de família. Destacaram-se por apresentarem os maiores números de espécies as famílias, Fabaceae (quatro), Myrtaceae (três) e Sapindaceae (três) as quais representam $33 \%$ do número total de espécies encontradas. Flacourtiaceae, Moraceae e Solanaceae apresentaram duas espécies cada uma e 17 famílias apresentaram apenas uma espécie. Foram encontradas seis espécies exóticas, Pinus elliottii, Hovenia dulcis, Eriobotrya japonica, Morus nigra, Hibiscus rosa-sinensis e Citrus aurantium.

Através de observações e anotações feitas em campo, da discussão com especialistas e com base na Resolução CONAMA n. 002 de 18 de março de 1994 (Tabela 1), a área de Floresta Ombrófila Mista estudada apresenta vegetação secundária em estágio intermediário de 
regeneração, com árvores variando amplamente seus diâmetros e indivíduos de pequeno e médio porte.

TABELA 2 - LISTA DE ESPÉCIES IDENTIFICADAS NO REMANESCENTE DO CAMPUS DA UNIVERSIDADE TUIUTI BARIGÜI, CURITIBA, 2009.

\begin{tabular}{|c|c|c|c|c|c|}
\hline \multirow[b]{2}{*}{$\mathbf{N}^{\circ}$} & \multirow[b]{2}{*}{ Família } & \multirow[b]{2}{*}{ Nome Científico } & \multirow[b]{2}{*}{ Nome comum } & \multicolumn{2}{|c|}{ Estrato arbóreo } \\
\hline & & & & $\begin{array}{l}\text { Inferior } \\
(<15 \mathrm{~m})\end{array}$ & $\begin{array}{c}\text { Superior } \\
(15-20 \mathrm{~m})\end{array}$ \\
\hline 1 & AQUIFOLIACEAE & Ilex paraguariensis A.St.-Hil. & erva-mate & $\bullet$ & \\
\hline 2 & ANACARDIACEAE & Schinus terebinthifolius Raddi & aroeira & $\bullet$ & $\bullet$ \\
\hline 3 & ARAUCARIACEAE & $\begin{array}{c}\text { Araucaria angustifolia (Bertol.) } \\
\text { Kuntze }\end{array}$ & $\begin{array}{l}\text { pinheiro-do- } \\
\text { Paraná }\end{array}$ & $\bullet$ & \\
\hline 4 & ARALIACEAE & Tetrapanax papyrifer (Hook.) K. Koch & $\begin{array}{l}\text { arvore-do- } \\
\text { papel-de-arroz }\end{array}$ & $\bullet$ & \\
\hline 5 & ASTERACEAE & Piptocarpha axilaris (Less.) Baker & vassourão & $\bullet$ & \\
\hline 6 & EUPHORBIACEAE & Sapium glandulatum (Vell.) Pax & leiteiro & $\bullet$ & \\
\hline 7 & FABACEAE & Erythrina falcata Benth. & corticeira & & $\bullet$ \\
\hline 8 & FABACEAE & Ingá marginata Wild. & ingá & $\bullet$ & \\
\hline 9 & FABACEAE & Machaerium stipitatum (DC.) Vogel & sapuva & $\bullet$ & \\
\hline 10 & FABACEAE & Mimosa scabrella Benth. & bracatinga & $\bullet$ & $\bullet$ \\
\hline 11 & FLACOURTIACEAE & Casearia decandra Jacq. & guaçatunga & $\bullet$ & \\
\hline 12 & FLACOURTIACEAE & Casearia sylvestris Sw. & cafezeiro-bravo & $\bullet$ & \\
\hline 13 & LAURACEAE & $\begin{array}{c}\text { Nectrandra megapotamica (Spreng.) } \\
\text { Mez }\end{array}$ & canela-imbuia & $\bullet$ & $\bullet$ \\
\hline 14 & MALVACEAE & Hibiscus rosa-sinensis L. & hibisco & $\bullet$ & \\
\hline 15 & MELIACEAE & Cedrela fissilis Vell. & cedro & $\bullet$ & $\bullet$ \\
\hline 16 & MORACEAE & Morus nigra L. & amoreira & $\bullet$ & \\
\hline 17 & MORACEAE & $\begin{array}{c}\text { Sorocea bonplandii (Baill.) W.C. } \\
\text { Burger, Lanj. \& Wess. Boer }\end{array}$ & sororoca & $\bullet$ & \\
\hline 18 & MYRTACEAE & Eugenia uniflora L. & pitangueira & $\bullet$ & \\
\hline 19 & MYRTACEAE & MYRTACEAE 01 & & $\bullet$ & \\
\hline 20 & MYRTACEAE & Psidium cattleianum Sabine & araçá & $\bullet$ & \\
\hline 21 & PODOCARPACEAE & $\begin{array}{l}\text { Podocarpus lambertii Klotzsch ex } \\
\text { Endl. }\end{array}$ & pinho-bravo & $\bullet$ & $\bullet$ \\
\hline 22 & PINACEAE & Pinus elliottii Engelm. & pinus & $\bullet$ & $\bullet$ \\
\hline 23 & RHAMNACEAE & Hovenia dulcis Thunb. & uva-do-Japão & $\bullet$ & • \\
\hline 24 & ROSACEAE & Eriobotrya japonica (Thunb.) Lindl. & nespereira & $\bullet$ & \\
\hline 25 & RUBIACEAE & $\begin{array}{l}\text { Coussarea contracta (Walp.) Müll. } \\
\text { Arg. }\end{array}$ & & $\bullet$ & \\
\hline 26 & RUTACEAE & Citrus aurantium L. & laranja & $\bullet$ & \\
\hline 27 & SAPINDACEAE & $\begin{array}{l}\text { Allophylus edulis (A. St.-Hil., Cambess. } \\
\qquad \& \text { A. Juss.) Radlk. }\end{array}$ & vacum & $\bullet$ & $\bullet$ \\
\hline 28 & SAPINDACEAE & Cupania vernalis Cambess & cuvatã & $\bullet$ & \\
\hline 29 & SAPINDACEAE & Diatenopteryx sorbifolia Radlk. & maria-preta & $\bullet$ & \\
\hline 30 & SOLANACEAE & Solanum pseudoquina A. St.-Hil. & & $\bullet$ & \\
\hline 31 & SOLANACEAE & Solanum sanctaecatharinae Dunal & canema & $\bullet$ & $\bullet$ \\
\hline 32 & STIRACACEAE & Styrax leprosus Hook. \& Arn. & pau-remo & $\bullet$ & $\bullet$ \\
\hline 33 & TILIACEAE & Luehea divaricata Mart. & açoita-cavalo & $\bullet$ & $\bullet$ \\
\hline
\end{tabular}

Fonte: Pesquisa de campo

Foi possível verificar na área de vegetação arbórea (Figura 1) a ocorrência de dois estratos arbóreos distintos. No estrato arbóreo superior, com altura variando entre 14 e 20 metros, 
destacam-se algumas espécies nativas e representativas da cobertura original como Schinus terebinthifolius, Podocarpus lambertii, Luehea divaricata, Nectrandra megapotamica e Erythrina falcata representada por um indivíduo no dossel da floresta. Devido ao fato de o local de estudo estar situado dentro da área urbana, verificou-se grande interferência antrópica através da presença dominante da espécie exótica Hovenia dulcis, historicamente cultivada sem manejo adequado. Espécies invasoras são consideradas a segunda maior ameaça à biodiversidade. Quando estas possuem maior porte que a vegetação nativa produzem fortes impactos em função da alteração de dominância destas espécies, levando ao desaparecimento de espécies heliófitas nativas modificando a fisionomia da formação original (IAP, 2006).

O estrato arbóreo inferior, com altura variando entre oito e 13 metros, apresenta algumas espécies nativas dominantes, Allophylus edulis, Casearia decandra, Casearia sylvestris, Cedrela fissilis, Solanum sanctaecatharinae e também espécies exóticas, Eriobotrya japonica e Hovenia dulcis. Ilex paraguariensis, Eugenia uniflora, Psidium cattleianum e Coussarea contracta são espécies representativas de sub-bosque nativo.

Constatou-se a presença de indivíduos de Pinus elliottii alinhados (Figura 1), plantados sem técnicas silviculturais, com espaçamento inadequado e certamente não ocorreram desbastes e podas. Contou-se 82 indivíduos com circunferência a altura do peito (CAP) variando entre $56,1 \mathrm{~cm}$ e 267,5 cm. A ausência de técnicas silviculturais explica a grande variação de diâmetros do fuste dos indivíduos. O alinhamento dos indivíduos atravessa o local de estudo a partir da rua Pedro Leitoles em direção à Universidade. Kronka et al. (2005) descreve a madeira de pinus como importante fonte de matéria-prima na fabricação de produtos utilizados pela indústria moveleira e construção civil, entre eles: painéis (laminado, particulado ou fibras), fabricação de pasta celulósica para papel, madeira serrada e resinagem (medicinal, adesiva, tinta e solvente).

Os resultados obtidos por Barbosa et al. (2009) demonstram que o reflorestamento com Araucária angustifolia representa um "lar" para espécies nativas características desta formação florestal. Podendo ainda harmonizar interesses econômicos e conservação biológica. O pinheirodo-Paraná quando presente no estrato emergente $(25-27 \mathrm{~m})$, imprime um aspecto fisionômico peculiar à vegetação original (KOZERA, 1997). No local de estudo o pinheiro-brasileiro não aparece no estrato superior, havendo apenas alguns indivíduos juvenis com até quatro metros de altura, e outros indivíduos adultos dentro do campus, porém fora do capão constituindo árvores isoladas. Esta ausência de indivíduos representativos da cobertura original, provavelmente removidos durante o período de exploração da área, servirá como incentivo ao plantio, utilizando técnicas silviculturais desta espécie tão importante para as demais espécies da comunidade em questão. A retirada dos indivíduos de pinus e seu beneficiamento conforme alternativas citadas por Kronka (2005), e o reflorestamento por indivíduos de pinheiro-do-Paraná representa potencial econômico e de conservação, conforme Barbosa (2009).

Verifica-se também a presença de áreas em estágio inicial de regeneração (Figura 1), representadas por duas clareiras e uma área de vegetação rasteira no local. A primeira clareira situa-se junto à cerca que delimita o capão das residências do entorno (Rua Pedro Leitoles), onde existia uma horta agora abandonada, onde é possível verificar o início da sucessão ecológica, representado por gramíneas e "vassouras" (espécies da família Asteraceae). Algumas mudas foram plantadas nesta clareira e irão exercer função essencial na recuperação da mesma. A segunda clareira encontra-se 20 metros a oeste, atravessando o alinhamento dos indivíduos de Pinus elliottii, de tamanho menor em relação à primeira. Sua regeneração encontra-se em estágio mais avançado de sucessão, em relação à primeira, com algumas espécies arbóreas. A área de 
vegetação rasteira situa-se junto ao estacionamento e é dominado por espécies gramíneas. Ambas as áreas poderão ser manejadas com introdução de espécies nativas, visando o restabelecimento da cobertura original.

Verificou-se ainda a deposição irregular de entulho e de resíduos, sendo mais intensamente verificado próximo às residências (móveis, eletrodomésticos, resíduos de construção, roupas, entre outros), e também próximo à encosta que limita o bosque do mirante, destinado aos alunos, situado acima dos laboratórios da Universidade, (latinhas de refrigerante e copos plásticos, lâmpadas, pontas de cigarro foram os resíduos encontrados). Analisando as características dos resíduos encontrados fica evidente quem são os responsáveis pela deposição irregular dos mesmos. Por este motivo, ações de conscientização destinadas aos alunos e à comunidade se fazem necessárias. Isto deve partir do corpo docente e discente em conjunto, atendendo ao incentivo da Universidade.

Comparando-se a presente área de estudo aos levantamentos realizados por Borgo (2002) pode-se verificar a similaridade entre as espécies observadas nos levantamentos realizados por esta autora, conforme apresentado na tabela 3. Os fragmentos somam 144.7 ha. 
(Revista Eletrônica do PPGEAmb-CCR/UFSM) ISSN:

TABELA 3 - FRAGMENTOS FLORESTAIS EM CURITIBA, ORDENADOS POR CLASSIFICAÇÃO QUANTO A SUA CONSERVAÇÃO E TAMANHO, CURITIBA, 2002.

\begin{tabular}{|c|c|c|c|c|c|c|}
\hline Localidade & $\begin{array}{l}\text { Área } \\
\text { (ha) }\end{array}$ & $\begin{array}{c}N^{\circ} \text { de espécies } \\
\text { Nativas e } \\
\text { cultivadas }\end{array}$ & $\begin{array}{l}\text { Visitação } \\
\text { média }^{1}\end{array}$ & $\begin{array}{c}\text { Grau de } \\
\text { urbanizaçãõo }\end{array}$ & $\begin{array}{c}\text { Remanescentes } \\
\text { próximos }^{3}\end{array}$ & Conservação ${ }^{4}$ \\
\hline Parque Barigüi & 50,0 & $160^{*}$ & +++ & ++ & 1 & +++ \\
\hline $\begin{array}{l}\text { Bosque Reinhard } \\
\text { Maack }\end{array}$ & 7,8 & 20 & + & +++ & 0 & +++ \\
\hline $\begin{array}{l}\text { Bosque Jardim } \\
\text { Saturno }\end{array}$ & 4,3 & 30 & + & ++ & 1 & +++ \\
\hline $\begin{array}{c}\text { Bosque Capão } \\
\text { da Imbuia }\end{array}$ & 4,2 & 10 & ++ & ++ & 0 & +++ \\
\hline $\begin{array}{l}\text { Bosque da } \\
\text { Fazendinha }\end{array}$ & 7,3 & 19 & +++ & +++ & 1 & ++ \\
\hline $\begin{array}{l}\text { Capão do Jardim } \\
\text { Botânico }\end{array}$ & 6,6 & 21 & +++ & ++ & 1 & ++ \\
\hline $\begin{array}{l}\text { Bosque João } \\
\text { Paulo II }\end{array}$ & 4,8 & 21 & +++ & +++ & 0 & ++ \\
\hline $\begin{array}{l}\text { Capão de } \\
\text { Ciências } \\
\text { Biológicas }\end{array}$ & 2,7 & 14 & + & ++ & 1 & ++ \\
\hline $\begin{array}{c}\text { Capão de } \\
\text { Educação Física }\end{array}$ & 2,2 & 23 & ++ & ++ & 1 & ++ \\
\hline $\begin{array}{l}\text { Bosque de } \\
\text { Portugal }\end{array}$ & 2,1 & 7 & ++ & ++ & 0 & ++ \\
\hline $\begin{array}{l}\text { Capão Tuiuti } \\
\text { Barigüi }^{* *}\end{array}$ & 2,1 & 33 & + & ++ & 1 & ++ \\
\hline $\begin{array}{l}\text { Bosque } \\
\text { Gutierrez }\end{array}$ & 1,8 & 13 & +++ & ++ & 1 & ++ \\
\hline $\begin{array}{c}\text { Parque } \\
\text { Barreirinha }\end{array}$ & 27,5 & 29 & +++ & +++ & 0 & + \\
\hline $\begin{array}{l}\text { Parque São } \\
\text { Lourenço }\end{array}$ & 20,4 & 33 & +++ & +++ & 1 & + \\
\hline Bosque Alemão & 4,0 & 15 & +++ & ++ & 1 & + \\
\hline $\begin{array}{l}\text { Bosque Boa } \\
\text { Vista }\end{array}$ & 1,2 & 20 & ++ & +++ & 0 & + \\
\hline \multicolumn{7}{|c|}{$\begin{array}{l}\text { (1). +++: alta intensidade; ++: média intensidade; +: baixa intensidade } \\
\text { (2). Indica grau de urbanização ao entorno. +++: alto grau; ++: médio grau; +: baixo grau } \\
\text { (3). 0: não ocorrente; } 1 \text { : ocorrentes em pontos não muito distantes; } \\
\text { (4). +++: pouco alterado; ++: alterado; +: muito alterado } \\
(*) \text {. Dados publicados de Kozera (1997) } \\
(* *) . \text { Pesquisa de campo }\end{array}$} \\
\hline
\end{tabular}

Fonte: Adaptado de Borgo, 2002, dados publicados de Kozera, 1997 e pesquisa de campo.

Em estudo realizado no Parque Barigüi em 1997, Carina Kozera encontrou 640 espécies. Do total, 160 espécies arbóreas, 329 herbáceas, 92 arbustivas e 64 trepadeiras. O local apresentava associações entre vegetação secundária, estágios intermediários e avançados de sucessão. 0 fragmento é o maior do município de Curitiba e representa $34,5 \%$ do total de fragmentos 
representados na tabela 2, recebeu "nota" de conservação (+++: pouco alterado) dada por Borgo na tabela supra, pois apresenta três estratos arbóreos onde no estrato emergente (25-27 m) Araucária angustifólia é dominante, e devido a muitas das espécies coletadas por Kozera (1997) foram listadas como ocorrentes nestes tipos vegetacionais. O local do presente estudo é unido ao Parque Barigüi, portanto esperava-se encontrar muitas espécies iguais ao levantamento realizado no Parque. Espécies como: Podocarpus lambertii, Casearia sylvestris estão entre os indivíduos do estrato arbóreo superior (15-18 m) do Parque Barigüi e também no estrato arbóreo superior (15$18 \mathrm{~m}$ ) que neste caso representa o dossel do fragmento Tuiuti Barigüi. Para o estrato arbóreo inferior $(8-10 \mathrm{~m})$ também encontramos mesmas espécies, Casearia decandra, Eugenia uniflora, Solanum pseudoquina e também uma espécie exótica, Hovenia dulcis.

Os Parques da Barreirinha e São Lourenço representam juntos 33,1 \% do total de fragmentos listados. Receberam "nota" de conservação (+: muito alterado) de Borgo (2002), pois muitas espécies exóticas foram encontradas nos dois locais. A presença de áreas para recreação com gramado e árvores esparsas no Parque da Barreirinha e a ausência de remanescentes representativos no Parque São Lourenço foi decisivo nas respectivas "notas". A descaracterização quanto à vegetação original e ausência de sub-bosque composto por grama, pouca variação de altura dos indivíduos dos dois estratos presentes, muitas espécies exóticas e trilhas no interior destes fragmentos foram responsáveis pelas "notas" de conservação (+: muito alterado). Estes fragmentos representam $36 \%$ da área total dos fragmentos listados. De acordo com as características relacionadas aos fragmentos em grau de conservação (+: muito alterado), o fragmento Tüiuti Barigüi não foi incluído nesta classe.

O Bosque da Fazendinha recebeu "nota" de conservação (++: alterado) dada por Borgo (2002), apresentando no estrato arbóreo superior algumas espécies iguais ao do fragmento Tuiuti Barigüi, entre elas: Luehea divaricata e Podocarpus lambertii. No estrato arbóreo inferior também encontramos mesmas espécies, Cupania vernalis, Casearia sy/vetris, Casearia decandra e Alophyllus edulis. Para Borgo (2002) havia uma redução drástica na cobertura do estrato arbóreo superior nas bordas. A fragmentação é caracterizada quando uma pequena mata passa a estar cercada por áreas abertas e a partir disto alterações microclimáticas incidem na periferia do fragmento. Um aumento da incidência de luz solar no solo, em relação ao interior da floresta, resulta no aquecimento da temperatura do solo e do ar. Quando se trata de pequenos fragmentos (1 a 10 ha), os efeitos de borda incidem sobre toda a superfície do fragmento. O resultado de toda essa mudança do microclima e a queda de árvores pela exposição aos ventos pode causar uma mudança drástica na característica da vegetação, bem como da comunidade animal. Esse conjunto de alterações foi caracterizado por Fernandez (2004) como "efeitos de borda", caracterizando a morte da floresta de fora para dentro. As áreas de vegetação em estágio inicial de regeneração presentes no fragmento Tüiuti Barigüi potencializam a ocorrência de espécies invasoras, constituindo locais ideais para manejo visando à recuperação, através da introdução de espécies nativas pioneiras.

O Bosque João Paulo II foi caracterizado por Borgo (2002) apresentando três estratos. No estrato arbóreo superior Luehea divaricata e Schinus terebinthifolius são espécies encontradas também no fragmento Tuiuti Barigüi. A espécie exótica Hovenia dulcis também é singular aos dois levantamentos. No estrato arbóreo inferior deste local foram encontradas as mesmas espécies àquelas encontradas nos levantamentos realizados no Bosque da Fazendinha e fragmento Tuiuti Barigüi. O representante exótico singular aos levantamentos realizados no Bosque João Paulo II e capão Tuiuti Barigüi é a Eryobotria japonica. O Bosque Gutierrez segundo Borgo (2002) apresenta 
espécies representativas da vegetação original nos estratos arbóreos, superior e inferior. Nos levantamentos realizados no capão Tüiuti Barigüi, Bosque Guiterrez e Bosque João Paulo II foram encontradas as espécies exóticas Hovenia dulcis e Eryobotria japonica.

Em levantamento florístico realizado no "Capão da Educação Física" da Universidade Federal do Paraná em 1987, Cervi, Schimmelpfeng e Passos (1987) encontraram 40 espécies arbustivas e arbóreas. Estas se distribuíram entre 24 famílias. As famílias Myrtaceae e Asteraceae apresentaram maior número de espécies (quatro), concluindo que o capão apresentava vegetação secundária em estado avançado e deveria ser conservado e recuperado, pois desta maneira seria ideal para aulas de campo. O local de estudo avaliado por esta pesquisa apresentava uma área 0,5 ha maior que o fragmento Tuiuti Barigüi, porém, este último apresentou sete espécies a mais que o capão da Educação Física. Entretanto, os dados qualitativos obtidos por Cervi e por esta pesquisa são de comparação subjetiva, pois inferências das comunidades em questão, livres de influência subjetiva e passíveis de comparação entre si, necessitam do suporte de parâmetros fitossociológicos (GALVÃO, 1994). Mesmo assim, podemos concluir que o capão Tuiuti Barigüi apresenta menor número de famílias. Cervi, Schimmelpfeng e Passos (1987) descreveram ainda que o "Capão da Educação Física" é utilizado como passagem e também para recreação e lazer dos professores e alunos, e concluiu que isto é preocupante para a conservação da área. O capão Tuiuti Barigüi não é utilizado como recreação e lazer, sendo eventualmente utilizado como passagem. Com a implantação de trilhas utilizando técnicas adequadas, o capão poderá ser utilizado preferencialmente como local de pesquisa e desenvolvimento de práticas em Educação Ambiental. Borgo (2002) listou as espécies exóticas Eryobotria japonica e Morus nigra, não listadas no levantamento de Cervi et al. (1987). Estas duas espécies também aparecem no sub-bosque do fragmento Tuiuti Barigüi.

Britezz et al. (1995) citado por Kozera (1997) descreve os representantes típicos da Floresta Ombrófila Mista: Schinus terebinthifolius (aroeira), Capsicodendron dinisii (pimenteira), Casearia sylvestris (cafezeiro-do-mato), Ocotea puberula (canela-guaicá), Ilex paraguriensis (erva-mate), Jacaranda puberula (caroba), Eugenia uniflora (pitangueira), Allophylus edulis (vacum), Matayba elaeagnoides (camboatá), Luehea divaricata (açoita-cavalo), Sloanea lasicoma (sapopema), Roupala brasiliensis (carvalho-brasileiro), Cedrela fissilis (cedro), Zanthoxyllum rhoifolia (mamicade-porca), Zanthoxyllum kleinii (juvevê) e Drymis brasiliensis (cataia). O capão Tuiuti Barigüi apresenta sete das 16 espécies supra listadas, podendo ser considerado como representativo de Floresta Ombrófila Mista.

O Bosque do Jardim Botânico de Curitiba foi descrito por Borgo (2002), apresentando Floresta Ombrófila Mista Montana e Aluvial pouco alterada divida em três estratos. As espécies Schinus terebinthifolius, Cupania vernalis, Casearia sylvestris, Eugenia uniflora, Alophyllus edulis ocorreram também no sub-bosque do fragmento Tuiuti Barigüi.

Dos 16 fragmentos listados oito receberam "nota" de conservação (++: alterado) e representam $20 \%$ da área total dos fragmentos. Quatro destes fragmentos apresentaram visitação de intensidade alta. Quanto ao grau de urbanização de entorno seis fragmentos apresentaram (++: médio grau) e dois apresentaram (+++: alto grau). Com relação à ocorrência de fragmentos não tão distantes apenas dois fragmentos não apresentam outro fragmento próximo. Dentre todos os fragmentos que receberam a "nota" de conservação (++: alterado), o capão Tuiuti Barigüi foi o que apresentou maior número de espécies. 
Em comparação aos levantamentos realizados por Borgo (2002), Kozera (1997), Cervi, Schimmelpfeng e Passos (1987), o capão Tuiuti Barigüi pode ser classificado como local (++: alterado), com relação a "nota" de conservação.

Os locais listados por Borgo (2002) que receberam "nota" de conservação (+++: pouco alterado), são fragmentos que mantém características de formações originais, onde o pinheiro-doParaná se sobressai na formação em estrato emergente que alcança até 25 metros de altura e apresentam três estratos. Estes fragmentos com "nota" (+++: pouco alterado) representam 44\% da área total dos remanescentes, o maior valor percentual com relação à área total dos fragmentos listados.

De acordo com os dados publicados por Pereira (2004), 95,66 \% dos remanescentes florestais estão localizados em terrenos particulares. Alguns proprietários usufruem de uma redução garantida pela lei, de 30 \% no Imposto Predial Territorial Urbano (IPTU), para imóveis que mantenham a conservação dos bosques. Pereira (2004) ainda argumenta que o setor privado apresenta poucas iniciativas na conservação de florestas em áreas verdes urbanas, exceto as motivadas por aspectos históricos familiares, daquelas pessoas que ainda residem em locais anteriormente conservados por seus ancestrais. $O$ fragmento Tuiuti Barigüi apresenta potencialidades no que tange a exploração com fins econômicos aliado à preservação movida por aspectos históricos e/ou com fins acadêmicos.

\section{CONCLUSÃO}

O diagnóstico desenvolvido no local revelou a existência de 33 espécies, distribuídas em 30 gêneros e 23 famílias botânicas.

A comparação dos resultados obtidos com outros trabalhos desenvolvidos em Floresta Ombrófila Mista permitiu verificar que o capão Tuiuti Barigüi apresenta alto grau de influência antrópica, vegetação secundária em estágio intermediário de regeneração, com a presença de espécies exóticas dominantes no dossel da floresta, assim como espécies representativas de vegetação nativa no sub-bosque. A erradicação de todas as espécies exóticas invasoras constitui uma ação de caráter urgente.

A área apresenta potencial para tratamentos silviculturais com finalidade de recuperação, conservação e educação.

A implantação de trilhas possibilitará utilizar o capão para aulas de campo, bem como para instalação de experimentos. Um verdadeiro "laboratório a céu aberto" disponível à Universidade.

\section{REFERÊNCIAS BIBLIOGRÁFICAS}

BARBOSA, Carlos E. A.; BENATO, Taís; CAVALheIRO, A. L.; TOREZANI, José M. D. Diversity of Regenerating Plants in Reforestations with Araucaria angustifolia (Bertol.) O. Kuntze of 12, 22, 35, and 43 Years of Age in Paraná State, Brazil. Restoration Ecology, Vol. 17, No. 1, pp. 60-67. January, 2009.

BORGO, Marília. As comunidades de epífitos vasculares em fragmentos florestais no município de Curitiba, Paraná, Brasil. 2002. 73 folhas. Dissertação de Mestrado em Botânica - Universidade Federal do Paraná, Curitiba, 2008.

CURCIO, Gustavo R.;BONNET, Annete; PESTANA, Débora; SOUZA, Lígia; SOCHER, Luís G.; GALVÃO, Franklin;RODERJAN, Carlos V. Compartimentação Toposseqüencial e Caracterização Fitossociológica de um capão de Floresta Ombrófila Mista. Revista Floresta, Curitiba, PR, Vol. 32, No. 1, pp. 3-16. Junho, 2002. 
CURITIBA. Prefeitura Municipal. Legislação Municipal - Lei n. 9.806 de 03 de janeiro de 2000. Disponível em http://www.curitiba.pr.gov.br > Acesso em: 25 nov. 2009.

CURITIBA. Prefeitura Municipal. Serviço de geoprocessamento - mapas de localização das áreas verdes - bacias hodrográficas. Curitiba 2004.

CURITIBA. Secretaria Municipal do Meio Ambiente. Ortofoto 2007. Setor Acervo. Curitiba, 2007.

FERNANDEZ, Fernando A. S. O poema imperfeito: crônicas de Biologia, conservação da natureza, e seus heróis. $2^{\text {a }}$ ed. Curitiba: Ed. Universidade Federal do Paraná, 2004. p.145-258.

FIDALGO, O. \& BONONI, V. L. R. Técnicas de coleta, preservação e herborização de material botânico. São Paulo: Instituto de Botânica, 1989.

FUNDAÇÃO DA UNIVERSIDADE FEDERAL DO PARANÁ PARA O DESENVOLVIMENTO DA CIÊNCIA, DA TECNOLOGIA E DA CULTURA. Relatório Final - Diagnóstico e Monitoramento da Cobertura Vegetal da área de Influência Direta e Indireta do Vazamento de Óleo da Refinaria Presidente Getúlio Vargas - REPAR, Araucária/PR, Fase II - Diagnóstico, Curitiba/PR, Jan/2002, 63p.

FUPEF - FUNDAÇÃO DE PESQUISAS FLORESTAIS DO PARANÁ. Conservação do Bioma Floresta com Araucária: relatório final - Diagnóstico dos remanescentes florestais. 2 v. FUPEF, Curitiba. 2001.

GALVÃO, Franklin. Métodos de levantamento fitossociológico. In: A vegetação Nat. do estado do Paraná - Curitiba. IPARDES, CTD. p. 25-37, 1994.

GARCILLÁN, Pedro P.; REBMAN, Jon P.; CASILLAS, Francisco. Analysis of the non-native flora of Ensenada, a fast growing city in northwestern Baja California. Urban Ecosyst 15 pp. doi: 10.1007/s11252-009-0091-1. March, 2009.

GREY, Gene W.; DENEKE, Frederick J. Urban forestry. New York: John Willey, 1978. p. 15 -24.

GOGOLA, Wagner Luis. Manual básico de coleta, desidratação e montagem de exsicatas. Trabalho não publicado. 2009.

IAP. Unidades de conservação - Ações para valorização da biodiversidade. João Batista Campos; Márcia de Guadalupe P.Tussolino; Carolina Regina C. Müller - organizadores. Curitiba, Instituto Ambiental do Paraná, 2006. $344 \mathrm{p}$.

IAPAR. Cartas climáticas básicas do estado do Paraná. Londrina: Fundação Instituto Agronômico do Paraná, 1978.

IBGE - FUNDAÇÃO INSTITUTO BRASILEIRO DE GEOGRAFIA E ESTADO, DEPARTAMENTO DE RECURSOS NATURAIS E ESTUDOS AMBIENTAIS. Manual técnico da vegetação brasileira. 92 p. Rio de Janeiro, 1991.

KOZERA, Carina. Levantamento Florístico de um remanscente de Floresta Ombrófila Mista e áreas adjacentes no Parque Barigüi, Curitiba, Paraná, Brasil. 1997. 67 folhas. Monografia (Bacharelado em Ciências Biológicas, Universidade Federal do Paraná, Curitiba, 1997.

KRONKA, Francisco J.N.; BERTOLANI, Francisco; PONCE, Reinaldo H. A cultura do Pinus no Brasil. São Paulo: Sociedade Brasileira de Silvicultura, 2005. p. 10-35.

MAACK, Reinhard. Geografia física do Estado do Paraná. Curitiba: CODEPAR, 1968. 350p.

MISSOURI BOTANICAL GARDEN. Tropicos.org. Missouri Botanical Garden. Disponível em: http://www.tropicos.org > Acesso em: 27 Nov 2009. 
NEGRELLE, Raquel R. B.; LEUCHTENBERGER, Ramoci. Composição e estruturado componente arbóreo de um remanescente de Floresta Ombrófila Mista. Revista Floresta, Curitiba, PR, Vol. 31, No. 1 e 2, pp. 42-51. Junho, 2006.

PEREIRA, Mauri C. B. Política para a conservação de áreas verdes urbanas particulares em curitiba - Percepção dos proprietários de Imóveis na Bacia Hidrográfica do Rio Belém. 2004. 121 folhas.Dissertação de Mestrado em Ciências Florestais - Universidade Federal do Paraná, Curitiba, 2004.

RODE, Rafael. Avaliação florística e estrutural de uma Floresta Ombrófila Mista e de uma vegetação arbórea estabelecida sob um povoamento de Araucaria angustifolia de 60 anos. 2008. 159 folhas. Dissertação de Mestrado em Manejo Florestal - Universidade Federal do Paraná, Curitiba, 2008.

SANQUETTA, C.R.; DALLA CORTE, Ana P.; VULCANIS, Lisiane; BERNI, Diego M.; BISCAIA, Alberto G. Estabelecimento de Plântulas de Espécies Arbóreas em um Experimento de Controle de Taquaras (Bambusoideae) no Sul do Paraná, Brasil. Revista Ciências Exatas e Naturais, Vol. 8 n 2, Jul/Dez 2006. 